\title{
Equipment
}

\section{Oxygen concentrators: a primary oxygen supply \\ source}

R.M. Friesen MD FRCPC,

M.B. Raber PEng,

D.H. Reimer MD FRCPC

Purpose: Efforts to harmonize the standards of the CSA and the ISO, as they relate to compressed medical gas supply and piping, prompted us to review ten years experience with oxygen concentrators (OCs) in Canada used as a primary hospital oxygen supply. The goals of this study were; 1) To document the number of Canadian OC Hospital sites, 2) to define what impact these units have had on medical practice and patient care, and 3) to explore trends in oxygen costing and utilization at the study sites.

Methods: Following a four part mail survey and telephone follow up, site surveys were conducted for all hospitals utilizing an OC. Installation and service records, operating costs, amortization detail, leasing records as well as patient safety were all detailed.

Results: Forty eight of 52 Canadian hospitals utilizing an OC participated. Clinical activity at the surveyed sites of 1996 included 30,642 surgical operations, 9,415 intensive care bed days and 364,529 emergency room visits. The cumulative survey represents $1,026,819 \mathrm{hr}$ of OC operation. During a $24 \mathrm{hr}$ day, OCs operate $55 \pm 3 \%$ of the time. Financial analysis was validated at 43 of the 48 hospital sites. During the study the unit cost of oxygen was reduced by $62 \%(P<.0001)$. An annual increase in oxygen consumption of $11.5 \pm 2 \%$ was documented $(P<.0001)$. No patient care critical incidents related to OCs were reported.

Conclusion: An OC installation which is CAN/CSA Z305.6-M92 compliant provides a safe, reliable, cost efficient primary hospital source of oxygen.

Objectif : Les efforts pour harmoniser les standards de la ACN et de l'ISO, quant aux approvisionnements en gaz comprimés médicaux et leurs canalisations, nous incitent à revoir dix ans d'expérience avec les concentrateurs d'oxygène $(\mathrm{CO})$ au Canada, appareils utilisés comme source première d'oxygène dans les hôpitaux. Nos objectifs étaient de : 1) fournir le nombre de $\mathrm{CO}$ des sites hospitaliers canadiens, 2) définir l'influence de ces unités sur la pratique médicale et les soins aux patients et 3 ) explorer l'évolution du coût de l'oxygène et de son utilisation aux sites d'études.

Méthode : Après avoir posté le questionnaire d'enquête en quatre parties et avoir assuré le suivi par téléphone, les études ont été menées sur place pour tous les hôpitaux qui utilisaient un CO. Les bilans d'installation et de service, le coût d'opération, les détails de l'amortissement, les dossiers de crédit-bail aussi bien que les mesures de sécurité pour le patient ont été notés.

Résultats : Parmi les 52 hôpitaux canadiens qui utilisent un CO, 48 ont participé à l'étude. L'activité clinique aux sites d'enquête de 1996 comprend 30642 interventions chirurgicales, l'équivalent de 9415 jours de soins intensifs au lit et 364529 visites à la salle d'urgence. L'enquête complète représente I 026819 heures d'utilisation d'un $\mathrm{CO}$. Pendant les $24 \mathrm{~h}$ d'une journée, les $\mathrm{CO}$ fonctionnent pendant $55 \pm 3 \%$ du temps. L'analyse financière a été validée pour 43 des 48 sites hospitaliers. Pendant l'étude, le coût unitaire de l'oxygène a été réduit de $62 \%$ $(P<0,000 \mid)$. Une hausse annuelle de consommation d'oxygène de $11,5 \pm 2 \%$ a été observée $(P<0,000 \mid)$. Aucun incident grave relié à l'utilisation des $C O$ n'a été rapporté.

Conclusion : Une installation de CO qui répond aux normes Z305.6-M92 des CAN/ACN fournit une source principale d'oxygène sécuritaire, fiable et rentable en milieu hospitalier.

From the Department of Anesthesia, Faculty of Medicine, University of Manitoba, St. Boniface General Hospital, 409 Tache Avenue, Winnipeg, Manitoba R2H 2A6 Canada.

Address correspondence to: Dr. R.M. Friesen. Phone: 204-233-8563; Fax: 204-231-0640.

Supported by a grant from the Manitoba Provincial Ministry of Health.

Accepted for publication August 15, 1999 
$\mathrm{T}$

HE continuing efforts to harmonize the standards of the Canadian Standards Association (CSA) and the International Organization for Standardization (ISO), as they relate to compressed medical gas supply and piping, prompted us to review present Canadian experience with oxygen concentrators (OCs) used as a primary hospital oxygen supply. Canada has the greatest number of health care facilities in the world utilizing OCs as a primary source of oxygen supply, that have been installed to a National Standard. ${ }^{1}$ All systems are certified for use by a CSA medical gas testing agency and comply with CAN/CSA Z305.6. ${ }^{1}$

In 1987, the Province of Manitoba, after preliminary research and motivated by rapidly accelerating costs for supplies of cryogenic oxygen, embarked on establishing OCs for the provision of a primary supply of hospital oxygen. In 1992, the experience of 22 hospitals utilizing an $\mathrm{OC}$ as a primary source of oxygen supply was reported in the Canadian Journal of Anaesthesia. ${ }^{2}$ Recognition of the importance of OCs in hospital practice resulted in the development of a Canadian Standards Association standard. ${ }^{1}$ Specific reference to utilization of OCs is made in the Canadian Anesthesiologists' Society Guidelines to the Practice of Anesthesia. ${ }^{3}$ Use of USP $0_{2} 93^{4}$ as a primary hospital supply has then been established in Canada for more than ten years.

The goals of this study were; 1) To document the number of Canadian OC Hospital sites, 2) to define what impact these units have had on medical practice and patient care, and 3) to explore trends in oxygen costing and utilization at the study sites.

\section{Methods}

Utilizing manufacturer installation and service records as well as previously documented site information, all Canadian jurisdiction hospitals with an oxygen concentrator were identified as at December 31, 1996. A four part questionnaire was mailed to each site. The survey consisted of 74 questions. Individual sections requested replies from the hospital administrator (Part I), a medical practitioner (Part II), Biomedical Engineering/Physical Plant or Facilities Management personnel (Part III), and the Director of Finance (Part IV) (Table I).

Telephone follow-ups were made, for non-responders, to arrange on-site visits and to seek additional or to clarify information provided. Where possible, manufacturer or service providers' preventative maintenance service records were also reviewed.

Each site was then visited by either a research assistant or one of the principal investigators (RMF). This
TABLE I Summary of Oxygen Concentrator Questionnaire (by Category)

Part I ADMINISTRATION (completed by CEO or appointed representative)

- Current bed census (\# and category)

- ICU, Emergency and OR case loads

- Factors leading a particular facility to adopt oxygen concentrator technology

- $\quad$ Satisfaction indices relative to Economics, Reliability and Quality Assurance

Part II CLINICAL/MEDICAL (completed by Chief of Medical Staff and anesthesiologists)

- Medical staff familiarity with OCs and $0_{2} 93$

- Hospital obstetric/newborn health delivery

- Anesthetic machine, monitors and techniques employed on site

- Medical practice impacts of $0_{2} 93$ including survey for patient critical incidents

Part III INSTALLATION/OPERATIONAL PROCESSES

(completed by Director of Facilitics Management or assigned representative)

- Primary, secondary and reserve oxygen supply sources detailed

- Daily service function detailed as to personnel involved, time required and problems

- $\quad$ Preventative maintenance detailed as well as measures for product gas quality assurance

- OC "hours of operation" logged

Part IV OC FINANCE (completed by the Director of Finance or assigned representative)

- $\quad$ OC installation costs

- Ongoing annual operating costs*

- oxygen purchased to supply secondary and reserve supplies

- electrical consumption costs

- maintenance costs

- Cost of oxygen prior to OC installation

* Fiscal years 1994/95, 1995/96 and current year-to-date if available.

was done to verify and validate information provided on the questionnaire, to provide further detail information forms as well as to define operating costs. Operating costs were classified as direct operating costs such as service (parts and labour), back up oxygen if so configured, and electrical. Capital amortization (calculated assuming a ten year period) or alternatively, leasing costs, were recorded. Because each local configuration results in wide variation in "housing the system" the capital cost did not include building, electrical/ mechanical or other possible site installation expenditures. Service costs were determined by review of supplier invoices for parts, labour and travel. Servicing costs included at least two years experience for each site unless the time from OC commissioning to survey was 
TABLE II Canadian OC Health Care Facilities Summary

\begin{tabular}{ll}
\hline Number of Facilities & 52 \\
Sites Surveyed * & 48 \\
Hospital Size (beds) $\uparrow$ & 41 \\
Paticnt Bcds $\ddagger$ & 2,833 \\
Acute Carc Capacity Beds $\ddagger$ & 1,530 \\
Operating Room Theatres $\ddagger$ & 55 \\
Obstetrical (Labour and Delivery sites) $\ddagger$ & 150 \\
Emergency Room bays $\ddagger$ & 105 \\
Surgical Operations $\$$ & 30,642 \\
Intensive Care Bed days $\$$ & 9,415 \\
Emergency Room Visits $\$$ & 364,529 \\
\hline
\end{tabular}

Notes: * data validated at site visit

$\dagger$ median (range $10-318$ )

$\ddagger$ totals for sites surveyed

$\$$ clinical activity - 1996

of a lesser duration. Back up oxygen expenditures were determined by rental costs associated with maintaining the secondary and reserve supplies as well as the volume of oxygen used from these sources. Electrical costs were calculated based on; actual invoices, hours of operation of the OC (concentrator and compressor), specific electrical power loads and regional electrical utilities cost (consumption and demand).

Data management and analysis was by Microsoft Excel $\circledast$ V 7.0 and SPSS Base 8.0.

Parametric data are reported as means $\pm \mathrm{SE}$ and were analyzed using Student's t tests. $P<.05$ was considered statistically significant.

\section{Results}

Fifty two Canadian hospitals utilizing OCs as a primary source of oxygen were identified. Forty eight replied to our request for survey and returned the questionnaires as requested. In four cases, in spite of repeated mailing and telephone requests, we were unable to obtain a completed questionnaire, or arrange for a site survey. The survey response rate was $92 \%$. All sites surveyed operated CSA certified ${ }^{1}$ OCs providing $\mathrm{O}_{2} 93$ via previously installed $\mathrm{O}_{2} 99$ medical gas pipeline systems. ${ }^{5}$ In the case of Churchill and Baffin Regional Health Centres, the secondary and reserve oxygen supplies are also generated by the oxygen concentrator in conjunction with a high pressure oxygen booster. These centres also are able to supply type " $E$ " and type " $H$ " cylinders of $0_{2} 93$ to their remote nursing stations.

\section{Results Part 1 - Administrative}

Table II summarizes the hospital sites surveyed.

Hospital administrators reported that the decision to procure OC technology included; economics
(94\%), assured supply (73\%) and Department of Health recommendation $(85 \%)$.

Surveying the satisfaction of hospital administrators with the operation of OCs at each site, favourable responses were: Economics of operation (94\%), Reliability (90\%) and Quality Assurance (92\%). Full text commentary was very positive for $\mathrm{OC}$ sites, including unanticipated improvements to previous problem areas such as unpredictable $\mathrm{O}_{2}$ delivery and escalating costs experienced before the use of an OC as primary supply.

\section{Results Part II - Clinical/ Medical}

Seventy one percent of respondents were aware of $\mathrm{O}_{2}$ 93 at their hospital but only $23 \%$ stated that $\mathrm{O}_{2} 93$ was listed on the hospital formulary as required by CAN/CSA Z305.6.

Seventy three percent of the sites surveyed provided newborn health care. Fifteen of 38 centres reported the routine administration of oxygen to newborns.

Sixty five percent of the surveyed sites provided regular anesthetic services. Anesthetic delivery systems were 61\% Ohmeda ${ }^{\circledR}$ and 35\% Drager North America ${ }^{\circledR}$. All sites reported provision for capnography while $40 \%$ of the sites surveyed had anesthetic agent monitoring. Sixty four percent of these sites routinely used fresh gas flow rates of two or less litres per minute. There were no sites that reported the use of closed circuit anaesthesia techniques. Forty eight percent of medical staff reported anesthetic machine calibration for oxygen prior to use, the remaining sites reported reliance on scheduled preventative maintenance procedures. Six percent of the medical practitioners surveyed reported a "change in practice" as a result of the presence of an OC. This change was not detailed or quantified but included descriptions of more liberal oxygen prescription, the presence of a reliable oxygen supply at remote nursing stations as well as equipment calibration considerations.

There were no reported patient critical incidents related to the use of OCs.

\section{Results Part III Installation - Operational Processes}

At the 48 sites surveyed there are 53 operational OCs. The remote location of five facilities factored in the decision to duplex concentrators operating as the primary supply at these sites.

Rimer Alco North America and Air Sep are the manufacturers supplying OCs in the Canadian market. Forty eight of 49 Rimer Alco sites responded to the survey.

A critical component within an oxygen concentrator system is the compressed air supply. Of the 53 OCs, 47 of the systems now utilize a rotary screw compressor that is manufactured by Sullair $\circledast$. Several sites that originally utilized the oil-less reciprocating 
TABLE III OC's Utilization Indices

\begin{tabular}{lllll}
\hline & Pre OC & 1996 OC Data $\% \Delta$ & t test \\
\hline Recorded $0_{2}$ & & & \\
Consumption $\left(\mathrm{m}^{3}\right)$ & $9658 \pm 1472$ & $16073 \pm 2450$ & $66 \%$ & $P<.0001$ \\
Unit Cost $\mathrm{O}_{2}\left(\$ \mathrm{~m}^{-3}\right)$ & $4.53 \pm .69 *$ & $1.70 \pm .26 \dagger$ & $62 \%$ & $P<.0001$ \\
\hline Notes: & $\bullet \mathrm{n}=43$ \\
& $\bullet$ values mean $\pm \mathrm{SE}$ \\
& total $0^{2}$ purchase costs prior to $\mathrm{OC}$ installation \\
& $\dagger$ OC operating costs plus purchased $\mathrm{O}_{2}$ backup
\end{tabular}

TABLE IV Hospital Oxygen Source of Supply $\$$

\begin{tabular}{lll}
\hline & CAN/CSA Z305.1 & CAN/CSA Z305.6 \\
\hline Primary Supply & $*$ & 2 x average flow rate \\
Sccondary Supply† & $*$ & 2 days average oxygen \\
& & demand $\neq$ \\
Reserve Supplyt & Average one days & $\begin{array}{l}1.5 \text { day's average oxygen } \\
\text { demand }\end{array}$ \\
\hline
\end{tabular}

* Sized according to the health care facility

$\ddagger$ Local conditions such as geographic location or isolation may require greater secondary and reserve supplies

† Secondary and reserve supplies are usually $0_{2} 99$ but OCs can be configured to service same with $\mathbf{0}_{2} 93$

$\$$ Previously published ${ }^{2}$

compressor, and which subsequently converted to the rotary screw type compressor, commented on the improved reliability of the compressor as well as a reduced maintenance cost.

As per CAN/CSA Z305.6, the control system of each oxygen concentrator must include two independently operating oxygen analyzers continually monitoring and displaying the oxygen concentration. The oxygen analyzers were to meet specified requirements of CAN/CSA Standard Z168.6, ${ }^{6}$ except that the maximum error was not to exceed $1 \%$ oxygen. All of the sites reported using duplex Servomex® Model 571 analyzers. No concerns or critical incidents were identified relative to the Servomex's operation and/or accuracy. Fluctuations in barometric pressure can result in calibration drift of the Servomex $571 \otimes$.

Forty five sites utilized high pressure $(\mathrm{H}$ or $\mathrm{K})$ size oxygen cylinders as a secondary supply. Three sites reported using a liquid bulk tank as the secondary supply. All of the sites utilized high pressure cylinders for the reserve supplies.

All sites reported that the systems had been installed to the CAN/CSA Standard Z305.6 and further that they had been tested and certified for use by a Medical Gas Testing Agency accredited by CSA.
Staff responsible for daily calibration and/or maintenance of the OC varied widely but they were always personnel already on site at each health care facility. Thirty six of 48 sites surveyed estimated the average time required; to check the OC operation, calibrate the oxygen analyzers and to $\log$ this activity, at between ten and twenty minutes per day. Although not factored into the costing, this time was reported to be reduced compared to maintaining a high pressure cylinder bank. Forty seven of 48 sites calibrated the oxygen analyzers daily. Forty of 48 sites had a manufacturers' regular preventative maintenance contract with terms of regular service between one and three times annually.

For the sites surveyed, as at December 31, 1996, there were more than $1,026,819 \mathrm{hr}$ of OC operation over $2,599 \mathrm{mo}$. For all the sites in this survey the monthly operation is $20,822 \pm 1863 \mathrm{hr}$. During a 24 hr day, OCs operate $55 \pm 3 \%$ of the time.

Many $O C$ sites have access to cryogenic oxygen supplies in order to service secondary and reserve stores. Six of the 48 sites were more than $250 \mathrm{~km}$ from such a supply while 16 are $100-250 \mathrm{~km}$ away. In four locations access is limited to annual sea lift, air, rail or all- terrain vehicle.

There were no reported cases of loss of oxygen supply. Ten sites reported one incident of high utilization of secondary supply (HUSS) caused by a demand for oxygen that exceeded the output of the concentrator for an extended period of time. In no instance did this recur and was always correlated to specific circumstances such as unusual peak demand (secondary supply utilization as per CAN/CSA Z305.6) or failure to keep sufficient back up quantities of oxygen in storage relative to the suppliers delivery schedule. All of these sites were configured with an OC added to a previous medical gas system.

HUSS sites were similar to all other sites regarding; hours of OC use $(25,709 \pm 4003 \mathrm{hr} v s 20,904 \pm 4694$ $\mathrm{hr})$, months in service $(61 \pm 8 \mathrm{mo} v 54 \pm 10 \mathrm{mo})$ and percent total run time $(58 \pm 4 \%$ ps $55 \pm 7 \%)$. (P.NS)

Twenty one of the 48 sites reported an annual product gas analysis. All samples were reported to comply with CAN/CSA Z305.6. An additional 10 sites had recently also instituted a policy of annual product gas sampling.

Forty seven of 48 sites gave the OCs an overall rating of satisfactory to excellent. All sites were satisfied with the safety and quality assurance afforded by these systems.

\section{Results Part IV - OC Finance}

We were able to validate financial information on 43 of $\mathbf{4 8}$ hospital site surveys returned (Table III). Before 


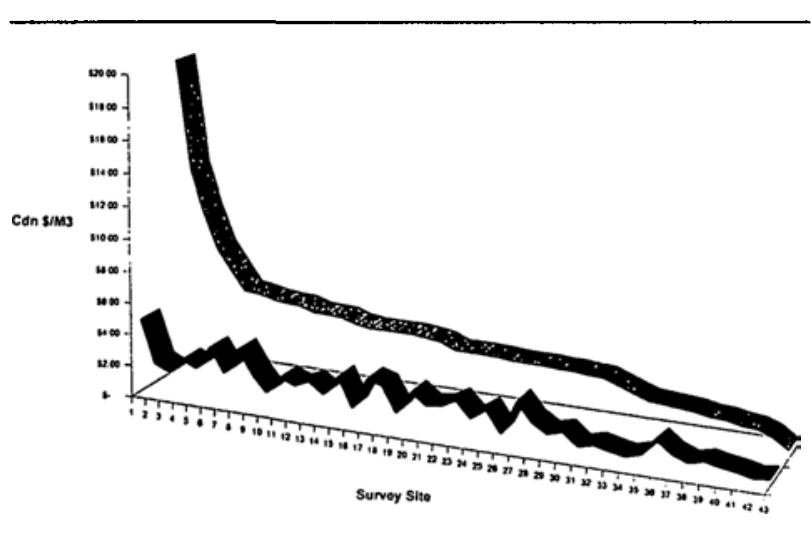

FIGURE

$\mathrm{Y}$ axis - Unit cost $0_{2} \$ \cdot \mathrm{m}^{-3}$

$\mathrm{X}$ axis

Upper graph - hospital sites rank ordered by pre $\mathrm{OC}$ unit $\mathrm{O}_{2}$ cost

Lower graph - unit $\mathrm{O}_{2}$ cost with OC

OC installation these hospitals utilized 415,276 cubic metres of oxygen at an annual cost of $\$ 1,285,139.00$. During the 1996 study year after $57 \pm 9$ mo of operation, annual $\mathrm{O}_{2}$ utilization had increased to 691,150 cubic metres of oxygen for a total cost of $\$ 674,809.00$. Liquid and high pressure cylinder oxygen purchased as backup in the amount of $\$ 82,098$ are included in the 1996 costing. Over the course of the survey period the unit cost of oxygen to health care facilities utilizing an OC was reduced by $\$ 2.83 \pm$ .43 or $62 \%(\$ 4.53 \pm .69$ vs $\$ 1.70 \pm .26)$. Survey sites were ranked according to their pre OC unit cost of oxygen. This was then compared with the 1996 unit oxygen costs. The sites with the highest pre OC unit cost, identified as sites $\mathbf{1}-\mathbf{3}$ in the Figure, were Gillam (Mb), Baffin Regional (Iqaluit, Nunavut) and Churchill $(\mathrm{Mb})$. These sites are all geographically remote with attendant high transportation costs.

With the exception of health care facilities that markedly reduced their clinical activity, there was an annual increase of $\mathrm{O}_{2}$ consumption. Including these sites $(n=43)$ this increase was $11.5 \pm 2 \%$ annually $(P$ $<0.0001$ ). In spite of this progressive increase in oxygen utilization, only four of 48 sites determined it to be necessary to increase their OC capacity as per guidelines for OC sizing included in CAN/CSA Z305.6 Appendix C. ${ }^{1}$ This was accomplished by either increasing the size of the $O C$ or alternatively duplexing the $\mathrm{OC}$ configuration.

\section{Discussion}

Oxygen concentrators installed to CAN/CSA Standard Z305.6 are safe, reliable and cost effective. When considering a primary oxygen supply, OCs should be ranked equal to other bulk oxygen supply systems. However, they offer distinct advantages regarding cost and availability of supply.

The Figure and Table III demonstrate some of the "inflation proofing" afforded by the use of an OC. Although oxygen utilization increased by an average of $11 \%$ per annum, the majority of sites $(44 / 48)$ did not require $\mathrm{OC}$ enhancement. With the use of an $\mathrm{OC}$, geographic remote location no longer becomes a major determinant in the unit cost of oxygen. As demonstrated in the Figure, not only does oxygen unit cost decrease with the use of an $\mathrm{OC}$, costs are similar among OC equipped hospitals regardless of location. By providing an alternative oxygen source, competitive market forces have reduced oxygen supply costs in many jurisdictions. This study was not able to quantify these reductions accurately. Some sites reported manufacturer unit oxygen cost reductions in excess of $200 \%$ at the time of tendering of an $\mathrm{OC}$.

For the time of this review, there were no reported adverse patient events attributed to oxygen source of supply. On the contrary, many sites commented on the increased level of patient care afforded by a less expensive, reliable and readily available oxygen supply.

From the results of the annual purity samples, there is no evidence that the use of a rotary screw, oil lubricated compressor, with oil removal filtration, in any way effects the quality of the oxygen produced by the oxygen concentrators. However, it should be noted that only 31 of 48 surveyed sites submitted an annual product gas sample for analysis as required by CAN/CSA Z305.6.

During the development of CAN/CSA Z305.6, detailed discussion and consideration were directed towards use of the existing hospital pipeline. ${ }^{5}$ This would necessitate the mixing of $0_{2} 93$ and $0_{2} 99$ within the same system. Health and Welfare Canada stated that, from a point of patient safety, this was acceptable. All hospital sites detailed in this study utilized their existing oxygen pipeline $^{5}$ and terminal units ${ }^{7}$ with the knowledge that $0_{2} 93$ and $0_{2} 99$ would mix during normal operation. In the clinical setting one cannot differentiate the oxygen source of supply. Equipment calibration however requires a gas of defined composition.

An $\mathrm{OC}$ does have anesthetic practice implications. These have been reviewed previously ${ }^{2}$ and are addressed by the Canadian Anesthesiologists' Society Guidelines to Practice. ${ }^{3}$ Total fresh gas flows of $<1 \mathrm{~L} \cdot \mathrm{min}^{-1}$ will result in the accumulation of Argon in the anesthetic circuit. This is easily detected by monitoring inspired 
oxygen and corrected by increasing fresh gas flow. Argon accumulation does not occur if fresh gas flow is $>1 \mathrm{~L} \cdot \min ^{-1} .8,9$

The Canadian Anesthesiologists' Society Guidelines to Practice delineates the requirement of an anesthetic machine check prior to the administration of an anesthetic. ${ }^{3}$ Only $48 \%$ of medical practitioners surveyed stated that they calibrated their anesthetic machine oxygen monitors prior to use. Although this study was not designed to quantify compliance to Practice Guidelines, it is of concern that at half of the sites surveyed, anesthetic machine checks were incomplete or not done routinely.

Does a hospital oxygen concentrator primary supply require redundancy? CAN/CSA Z305.6 does not require this, nor are the majority of sites so configured. Forty three of forty eight sites surveyed have a single appropriately sized, OC (primary supply). This study confirms excellent experience with this single OC configuration. All sites comply with CAN/CSA Z305.1, having a primary, secondary and reserve oxygen system. Five sites have a duplexed $O C$ configuration.

CAN/CSA Z305.6 permits one or more OCs as the primary oxygen supply. The primary supply must be sized to provide twice the average flow requirement and must have an appropriately sized storage tank to provide short-duration peak flows. The secondary and reserve supplies must be capable of supplying the anticipated peak flow requirement. The combination of the primary and secondary supplies form the operating supply. It is intended that the secondary supply may provide the sustained high demand flows that are greater than the capacity of the primary supply with its fixed flow output capacity. Table IV, published previously by the principle author ${ }^{2}$ summarizes present CAN/CSA Z305.6 required capacities for primary, secondary and reserve oxygen.

CAN/CSA Z305.6 does not dictate OC design, but does specify that the product gas concentration be greater than or equal to $93 \%$ oxygen. This must be continuously monitored by duplexed oxygen analyzers $^{6}$ with an accuracy of $\pm 1 \%$. There were no patient critical incidents related to low oxygen supply purity.

An integral part of an $\mathrm{OC}$ is the air compressor. Our study noted enhanced reliability in sites utilizing rotary screw technology with oil removal filtration. This is in compliance with CAN/CSA Z305.6.

In summary, an $O C$ installation which is CAN/CSA Z305.6 compliant provides a safe, reliable, cost efficient primary hospital source of oxygen.

\section{Acknowledgments}

The authors gratefully acknowledge the secretarial support of Mrs. Anne Cameron as well as the numer- ous technical insights and suggestions from Mr. R. Bradley, Iqaluit, Nunavut.

\section{References}

I Medical Oxygen Concentrator Central Supply System: For Use with Nonflammable Medical Gas Piping Systems. CAN/CSA Standard Z305.6-M92 Rexdale: Canadian Standards Association, 1992.

2 Friesen RM. Oxygen concentrators and the practice of anaesthesia. Can J Anaesth 1992; 39: R80-4.

3 CAS Guidelines to the Practice of Anaesthesia. Can J Anaesth 1998; 45(Suppl): 1-50.

4 The United States Pharmacopeia, The National Formulary. Rockville, Md. United States Pharmacopeial Convention, Inc. 1998; 18: IV/360.

5 Nonflammable Medical Gas Piping Systems. CAN/CSA Standard Z305. 1-84. Rexdale: Canadian Standards Association, 1984.

6 Oxygen Analyzers. CAN/CSA Standard Z168.6-M89. Rexdale: Canadian Standards Association, 1989.

7 Medical Gas Terminal Units. CAN/CSA Standard Z305.5-M86. Rexdale: Canadian Standards Association, 1986.

8 Parker CJR. The Anaesthetist's experience of PSA oxygen: the problem of argon accumulation in low flow anaesthesia. Health Service Estate (HSE) 1987; 61 : 65-70.

9 Parker CJR, Snowdon SL. Predicted and measured oxygen concentrations in the circle system using low fresh gas flows with oxygen supplied by an oxygen concentrator. Br J Anaesth 1988; 61: 397-402. 